\title{
EACOL (Scale of Evaluation of Reading Competence by the Teacher): evidence of concurrent and discriminant validity
}

This article was published in the following Dove Press journal:

Neuropsychiatric Disease and Treatment

10 October 2012

Number of times this article has been viewed

\section{Hugo Cogo-Moreira' \\ George B Ploubidis ${ }^{2}$}

Clara Regina Brandão de

Ávila ${ }^{3}$

Jair de Jesus Mari'

Angela Maria Vieira

Pinheiro ${ }^{4}$

'Department of Psychiatry, Federal University of São Paulo, São Paulo,

Brazil; ' ${ }^{2}$ Department of Population Studies, University of London, London, UK; ${ }^{3}$ Department of Hearing and Speech Pathology, Federal University of São Paulo, São Paulo, Brazil; ${ }^{4}$ Department of Psychology, Federal University of Minas Gerais, Belo Horizonte, Brazil
Correspondence: Hugo Cogo-Moreira Department of Psychiatry, Federal University of São Paulo. Rua Borges Lagoa, 570, $1^{\circ}$ Andar, São Paulo, Brazil Tel +55 II 982083526

Email hugocogobr@gmail.com
Aim: The study aimed to provide information about the concurrent and discriminant validation of the Scale of Evaluation of Reading Competence by the Teacher (EACOL), which is composed of 27 dichotomous items concerning reading aloud (17 items) and reading silently (10 items).

Samples: Three samples were used in this validation study. The first was composed of 335 students with an average age of 9.75 years $(\mathrm{SD}=1.2)$ from Belo Horizonte (Minas Gerais State), Brazil, where the full spectrum of reading ability was assessed. The second two samples were from São Paulo city (São Paulo State), Brazil, where only children with reading difficulties were recruited. The first São Paulo sample was labeled "SP-screening" and had n $=617$, with a mean age of 9.8 years $(\mathrm{SD}=1.0)$, and the other sample was labeled "SP-trial" and had $\mathrm{n}=235$, with a mean age of 9.15 years $(\mathrm{SD}=0.05)$.

Methods: Results were obtained from a latent class analysis LCA, in which two latent groups were obtained as solutions, and were correlated with direct reading measures. Also, students' scores on the Wechsler Intelligence Scale and on the Strengths and Difficulties Questionnaire tested the discriminant validation.

Results: Latent groups of readers underlying the EACOL predicted all direct reading measures, while the same latent groups showed no association with behavior and intelligence assessments, giving concurrent and discriminant validity to EACOL, respectively.

Conclusion: EACOL is a reliable screening tool which can be used by a wide range of professionals for assessing reading skills.

Keywords: school children, latent class analysis, assessment, reading difficulties, validation

\section{Background}

Evaluations and assessments by teachers are used to make educational decisions regarding students and to provide feedback to them, as well as to parents and school psychologists. ${ }^{1,2}$ Teachers' reports can thus serve as a primary source of information in the educational setting ${ }^{3}$ and play a very important role in assessment of emergent literacy. $^{4}$

The key issue that emerges in the educational context concerns the validity and reliability of teachers' evaluations and the contrast between this type of indirect assessment and direct forms, involving the use of both behavioral methods and structured tasks, such as the number of correctly read words per minute from a list of real words. ${ }^{4}$

A review of 16 studies concerned with the association between teachers' evaluations and test scores obtained by students revealed a high level of validity for teachers' assessment measures, but, at the same time, showed high variability in reliability. The range of correlation for the indirect comparisons (teachers were asked to use a rating 
of achievement in reading, math, social science, and language arts) was 0.28 to 0.86 , whereas the direct tests (teachers were directly asked to estimate the achievement test performance of their students, for example, the number of problems on an achievement test that each student solved correctly) yielded a range from 0.48 to $0.92 .^{3}$

Twenty years after this seminal work, a study showed that the predictive validity of teachers' reports for assessing emergent literacy skills of preschoolers was positive, with moderate to large effects between teachers' evaluations and children's performance. ${ }^{5}$ However, there is a shortage of studies that provide good psychometric evidence for the tools that indirectly assess children's reading performance, in spite of the increased demand for such instruments, especially ones that can effectively identify children at risk for future reading difficulties. ${ }^{6}$

Recently, to this end, one study has shown that judgements of the teachers about their students' progress that was based on a criterion-referenced assessment (children's phonic skills and knowledge), was better than most formal tests in the identification of those who later experienced reading difficulties. ${ }^{7}$

The early identification of these problems, through reliable measures with psychometric properties based on theoretical and empirical evidence, may play a key role in prevention. However, there is limited evidence about whether intervention can prevent the development of dyslexia and/or reading comprehension impairment in children early identified as at risk for reading difficulties. ${ }^{8}$

In Brazil, there is a lack of tools that are based on teachers' evaluations and that have good psychometric properties and theoretical foundations underlying the latent construct of reading competence. For example, one study found that teachers' reports, although reliable as a whole, failed to identify specific reading difficulties in a number of children, and concluded that such conditions would only be detectable via functional analysis of the reading processes, ${ }^{9}$ or by offering teachers a criterion-referenced instrument to help guide their judgment about the reading skills of students. ${ }^{10,11}$

\section{EACOL}

In order to implement this criterion, the authors developed the Scale of Evaluation of Reading Competence of Students by the Teacher (in Brazilian Portuguese: Escala de Avaliação de Competência em Leitura de Alunos pelo Professor [EACOL]), which evaluates reading aloud (RA) and silent reading $(\mathrm{SR})$ in elementary-school children. The preliminary version of EACOL was tested by De Salles and Parente ${ }^{12}$ in 2007, during which they found significant associations between students' performances in reading and writing words (as well as text comprehension) and teachers' perceptions of these skills via the EACOL. The teacher, once assisted by a set of well-defined criteria, becomes then more capable of rating the reading and spelling performances of their students.

\section{Development of the EACOL}

To develop the EACOL, information such as the teacher's experience, as well as a literature review about word recognition and comprehension, were considered. Elements that were thought to describe the RA and silent reading SR skills of elementary school children were obtained to formulate 57 items. ${ }^{11}$ An operational definition of criteria for classification of readers into three categories was proposed: (1) good reader, (2) not-so-good reader, and (3) poor reader. In each category, items were subdivided into items about RA, and items about SR.

Ten independent experts (linguists and psychologists) who were specialists in psychological assessment and development of reading were asked to evaluate the relevance and applicability of items and criteria of reader ability. The experts were asked to grade each item's pertinence from 1 to 5 (where 1 meant low and 5 very high relevance) to determine the importance of each criteria in defining the evaluation of reading competence by teachers. In addition, the experts were invited to suggest other relevant items and/or modifications to the list.

Following this procedure, the EACOL was designed to have two forms: A and B. Form A was developed to evaluate children's reading skills in the final phase of literacy (approximately 7 years old). Form B was developed for children who are completely literate. Recently, the scale underwent a final adjustment. ${ }^{13}$ In the current paper, we considered only form B (aimed at children from 8 to 10 years old).

Form B includes 27 items, 17 of which tap into the competence of reading aloud. Six of these items describe good reading ability, five items describe not-so-good reading ability, and six describe poor reading ability. The remaining ten items focus on SR; of these, four items describe good reading ability, three items describe not-so-good reading ability, and the remaining three items describe poor reading ability. The EACOL is provided in the Supplementary material (Figure S1).

The EACOL has not yet been applied in any language other than Brazilian Portuguese. The translation into English was carried out in the following three steps by the last author: translation from Portuguese to English, back-translation by 
a linguist, and correction and semantic adaptation where necessary.

The EACOL has not previously been submitted to a large-scale test of both concurrent and discriminant validity (the former is appropriate for test scores that will be employed in determining children's current status with regard to reading skills; the latter is the evidence of low correlation between measures that are supposed to differ [ie, EACOL not being correlated to psychiatric symptoms or intelligence]); ${ }^{14}$ as such, the objectives of this study were: (1) to identify subtypes of readers through use of the EACOL; (2) to describe the associations between the subtypes of readers found in this indirect measure of reading and various measures directly related and unrelated to reading; and (3) to verify whether the EACOL is sensitive to changes in instructions. Therefore, our hypotheses were: (1) If the EACOL is a useful screening tool for assessing reading skills of readers in grades two to four, latent groups of readers showing different levels of reading ability will be found; (2) if the students judged by the teachers using the EACOL as good, not-so-good, or poor readers show corresponding performance in direct measures of reading, this will be taken as concurrent validity for the instrument. Similarly, discriminant validity will be granted if no associations are found between the reading ability of the sample, and behavior and intelligence assessments; and (3) if the EACOL is sensitive to changes in instructions, the number of latent groups found will vary in accordance with the instructions given. That is, it was expected that a best-fit model with three latent groups of readers would be obtained when no specific direction in instruction was given to the teachers, and that lesser latent groups would emerge in situations in which teachers were explicitly asked to think of a particular type of reader, whether good or poor.

\section{Methods}

\section{Sample recruitment}

Three samples were used in this validation study: one from Belo Horizonte (Minas Gerais State) and two from São Paulo city (São Paulo State).

The first sample, called the BH-sample, was the main reference sample. This was constituted by 335 children, students on average 9.75 years old $(\mathrm{SD}=1.2)$ from second to fifth grade at five schools. Their teachers $(n=42)$, who agreed to participate through informed consent, were asked to complete the EACOL with the following instructions: "Please classify each of your students, according to the criterion presented. For each item please answer 'Yes' if it describes the reading ability of the student being evaluated and 'No' otherwise. Thank you for your collaboration."

Of the São Paulo samples, the main one was constituted by 235 children aged 8 to 10 years old, from ten public schools located in impoverished areas in the outskirts of the city of São Paulo, which was part of a screening sample obtained from 617 children $($ mean $=9.8$ years old $[\mathrm{SD}=1.0]$ ). The 48 teachers, from the second to fourth grades of these ten schools, were asked to complete the EACOL considering only the children with "a reading ability below the mean for the corresponding grade." This instruction was given to screen eligible children to take part in a separate randomized clinical trial about the effectiveness of music education in the improvement of reading skills among children with reading difficulties (ClinicalTrial.gov: NCT01388881 and Research Ethic Committee from Federal University of São Paulo CEP 0433/10). The 617 children in the sample formed what we called the São Paulo Screening Sample (SP-screening).

On the basis of the SP-screening, trained psychologists then ranked children who had the worst EACOL scores to identify, per school, a minimum of 24 children with reading difficulties to participate in the randomized clinical trial about the effectiveness of music education. Since the ten schools had different numbers of enrolled children, four schools did not meet the criteria of 24 children per school. In the other six schools, where the numbers of eligible children exceeded 24, a minimum of 24 and a maximum of 27 children were randomly selected via a lottery. After having identified the eligible children, the research team contacted the parents through an introductory letter that provided a description of the objectives of the trial and the informed consent. In the case of interest and acceptance by the parents, the children were considered included as participants.

To avoid bias related to cognitive problems in the SP-trial due to the nature of the experimental randomized clinical trial, the included children were tested for nonverbal intellectual ability using the Raven's Colored Progressive Matrices; ${ }^{15,16}$ and children with scores below the 25 th percentile were excluded. To avoid confounding due to contamination or overlap of interventions, parents were asked if their child was already receiving any regular hearing or speech therapy and/or music classes (such as private music classes, a social project involving musical learning, or other music schooling).

The total number of eligible children indicated by the teacher, selected by the psychologists as having the worst reading scores, and for whom parents returned authorization, was 240 . Out of these, two children were excluded because 
they had a score below the 25 th percentile, and three because they were already participating in social projects which involved musical learning and/or were under regular consultation with hearing and speech therapists. This left a sample of 235 children obtained from the SP-screening $(38.08 \%)$, who were classified as not so good and poor readers, with average age 9.15 years $(S D=0.05)$. We called this group the São Paulo Trial Sample (SP-trial).

Both the BH-sample and the SP-screening were taken as reference groups. Only the SP-trial sample was submitted to the study of the external validation of the EACOL (described below).

This protocol for the randomized clinical trial (SP-screening and SP-trial) was submitted to and approved by the Ethical Research Committee of the Federal University (CEP0433/10) of São Paulo (UNIFESP). The protocol for BH-sample was approved by the Ethical Committee from the Federal University of Minas Gerais (Process: n ETIC 347/04).

\section{Measures}

To evaluate the EACOL's discriminant validity, we used Intelligence Quotient (IQ) total score ${ }^{17}$ and the Strengths and Difficulties Questionnaire (SDQ), which was completed by teachers. ${ }^{18}$ The SDQ is a brief behavioral screening questionnaire comprising 25 items divided between 5 scales: emotional symptoms, conduct problems, hyperactivity/ inattention, peer relation problems, and prosocial behavior.

To test the concurrent validity of the EACOL, we selected a number of key variables to act as outcomes in the reading domain. These included:

- accuracy in the word task (rate of correct real words read per minute);

- accuracy in the nonword task (rate of correct nonwords read per minute); and

- accuracy in the text task (rate of correct words read per minute).

The word and nonword tasks ${ }^{19}$ consisted of a total of 88 words and 88 nonwords. The words varied in frequency levels of occurrence (high and low frequency words), ${ }^{19}$ bidirectional regularity (regular and irregular words according to graphemephoneme/phoneme-grapheme correspondence), ${ }^{20}$ and in length (short, medium, and long words, in terms of number of letters). The nonwords were built with the same Brazilian Portuguese orthographic structure and the same length of stimuli used in the word list. Here only the total number of correct words and nonwords read per minute in these tasks are considered; subgroup analysis related to regularity or irregularity or even word lengths were not conducted.
Psychometrically, the word and nonwords tasks showed excellent indices, presenting high correlation to each other ( $\mathrm{r}=0.92, P<0.001$ ), and moderately positive correlation with the Phonological Awareness Test ${ }^{21}\left(\mathrm{r}_{\text {accuracy of word }}=0.40\right.$ and $\left.r_{\text {accuracy of nonword }}=0.37\right)$. As expected, the general IQ was poorly related to word accuracy $(\mathrm{r}=0.168, P=0.01)$ and not correlated with nonword accuracy $(\mathrm{r}=0.01, P=0.131)$. Also, via Tobit regressions adjusted for the clusters of ten schools, schooling effects were observable in word accuracy through the academic years (ie, the higher education level, the better the achievement in the accuracy of words [third grade $\beta=6.62, P<0.01$; fourth grade $\beta=10.56, P<0.01]$ ) and in the accuracy of nonwords (third grade $\beta=4.45, P<0.001$; fourth grade $\beta=6.77, P<0.001$ ), corroborating for internal validation of both tasks.

Regarding the text that had to be read, a specific text was selected with consideration of the age of the child. The accuracy of text reading correlated highly with word accuracy ( $\mathrm{r}=0.916 ; P<0.001)$ and with nonword accuracy $(\mathrm{r}=0.873$; $P<0.001)$. The children's reading was audio-recorded for posttest analysis of accuracy.

Last, we included two covariates in the regressions models (described below). The first was visual acuity (ageappropriate) via Snellen chart, under conditions of monocular viewing, conducted by a technician in ophthalmology. The children were classified as having visual alterations or not. The second was the Simplified Central Auditory Assessment, ${ }^{22}$ conducted by a hearing and speech pathologist, which tested the elicitation of the auropalpebral reflex through instrumental sounds; sound location in five directions; sequential verbal memory for sounds with three and four syllables; and sequential nonverbal memory with three and four percussion musical instruments. The children were classified as having problems in central auditory processing or not.

\section{Statistical modeling}

To verify the number of latent groups in the three samples (BH-sample, SP-screening and SP-trial), we used latent classes analysis (LCA) on the 27 dichotomous items in the EACOL. The LCA is a form of cluster analysis initially introduced by Lazarsfeld and Henry in $1968 .{ }^{23}$ It is the most commonly applied latent structure model for categorical data, ${ }^{24}$ allowing the specification of statistical distributions through a model-based method, which differs from methods that apply arbitrary distance metrics to group individuals based on their similarity (for example, K-means clustering). ${ }^{25}$ In the LCA, unlike K-means clustering, a statistical model is built for the population from which the data sample was obtained. ${ }^{26}$ 
To compare LCA models with different numbers of latent classes, we used the Bayesian information criterion (BIC), in which small values correspond to better fit, as well as the sample size-adjusted BIC (ssaBIC). The classification quality of the model was evaluated with the entropy criterion, in which the values range from 0 to 1 , where values close to 1 indicate good classification. All LCA were conducted via Mplus version 6.12 (Muthén and Muthén, Los Angeles, CA). ${ }^{27}$

Both samples from SP were used to test whether the types of instructions that were given to the teachers would change the number of latent classes in comparison to the $\mathrm{BH}$ reference sample. Both concurrent and discriminant validity were assessed using a regressions model STATA version 12 (StataCorp, College Station, TX), considering robust standard errors to adjust for the cluster structure. Covariates such as age, sex, grade, and visual acuity and central auditory processing were considered in the regression models. It is important to emphasize that distributions, kurtosis, and skewness of the outcomes and covariates were checked to choose the better regression model. To optimize the visualization of the estimated probabilities as results of LCA, all "positive" EACOL items (eg, "reads with intonation compatible with punctuation marks;" "quickly reads 'new' and invented words;" "quickly reads 'known' and 'little- known' words") were reverse-scored for ease of interpretation. The recoded items were 3, 7, 12, 14, 15, 17, 20, 22, 23, and 25 .

\section{Results}

\section{Results of the LCA}

The LCA of BH suggested a good fit-model with three classes, while a two-class model for SP-screening and SPtrial was confirmed (Figures 1-3).

To establish which class corresponds to which category of reader, it is necessary to refer to Figures $1-3$, where the estimated probability axis has a scale from 0 to 1 . The former indicates good reading ability, while the latter represents reading disability.

In the BH-sample, a clear three-class solution is supported, considering empirical and theoretical elements.

For the SP-screening and SP-trial samples, the parametric bootstrap $P$-values for the likelihood ratio $\mathrm{X}^{2}$ goodness of fit

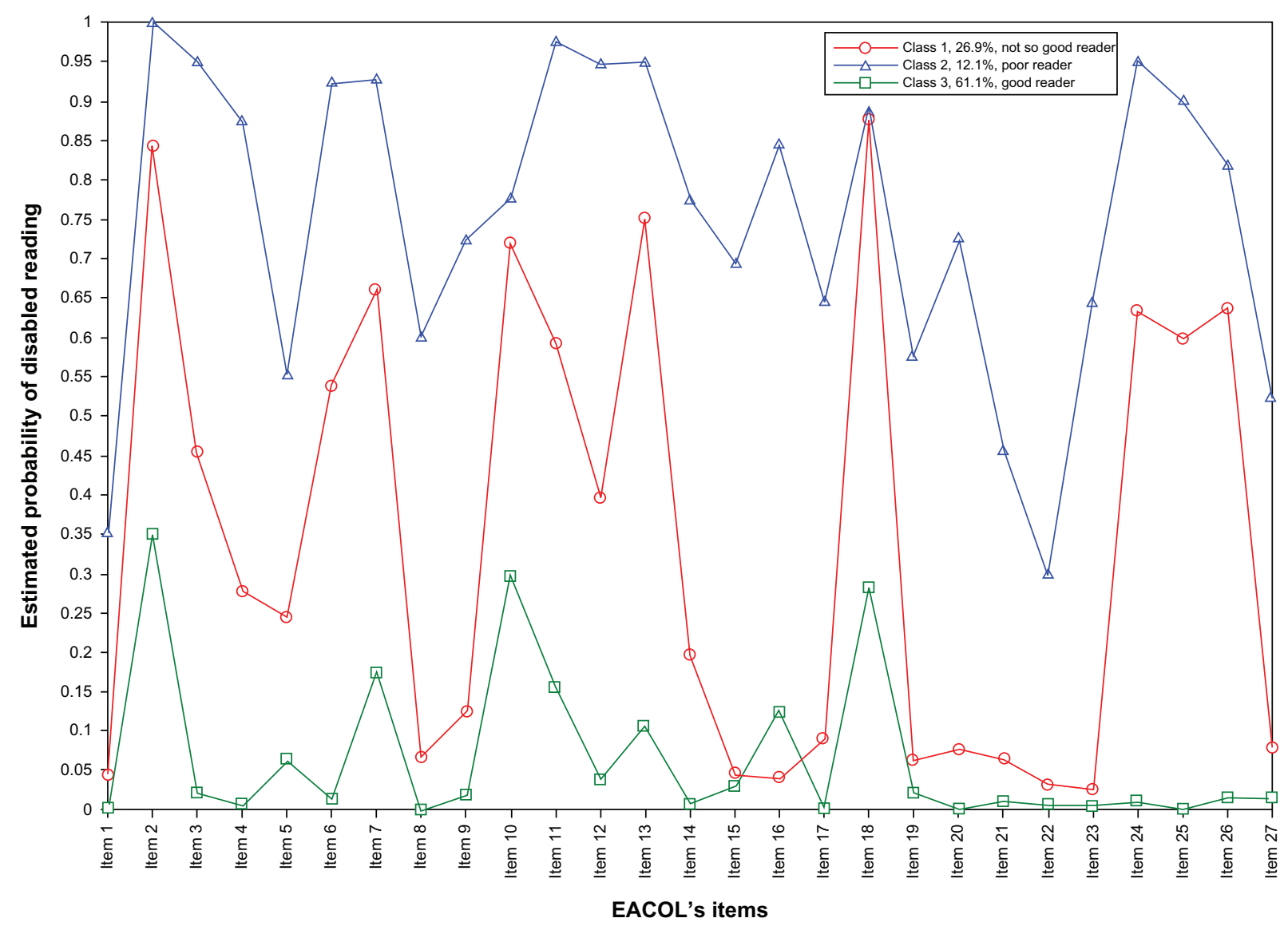

Figure I Latent classes analysis for $\mathrm{BH}$-sample.

Abbreviation: EACOL, Scale of Evaluation of Reading Competence by the Teacher. 


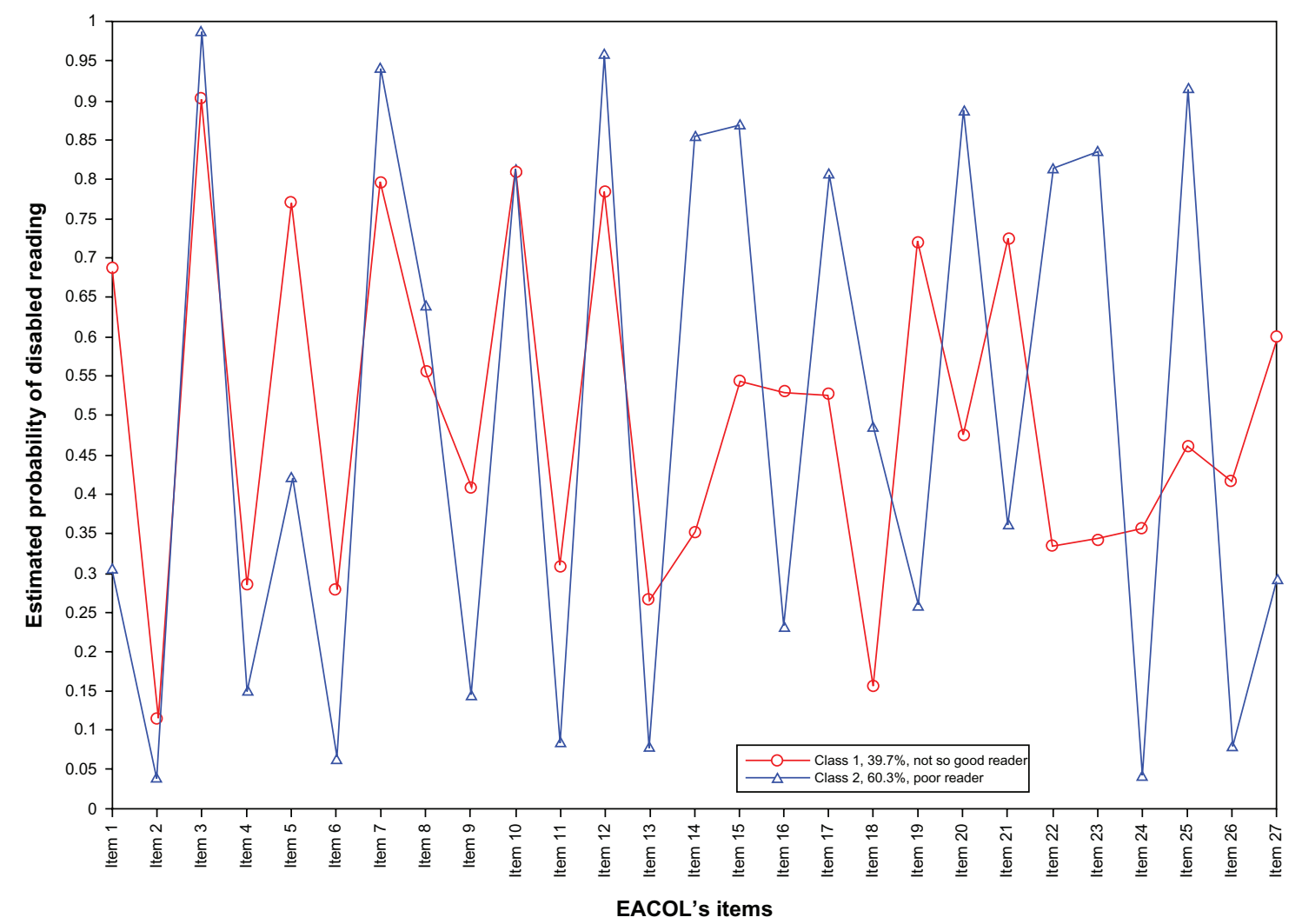

Figure 2 Latent classes analysis for the São Paulo Screening Sample.

Abbreviation: EACOL, Scale of Evaluation of Reading Competence by the Teacher.

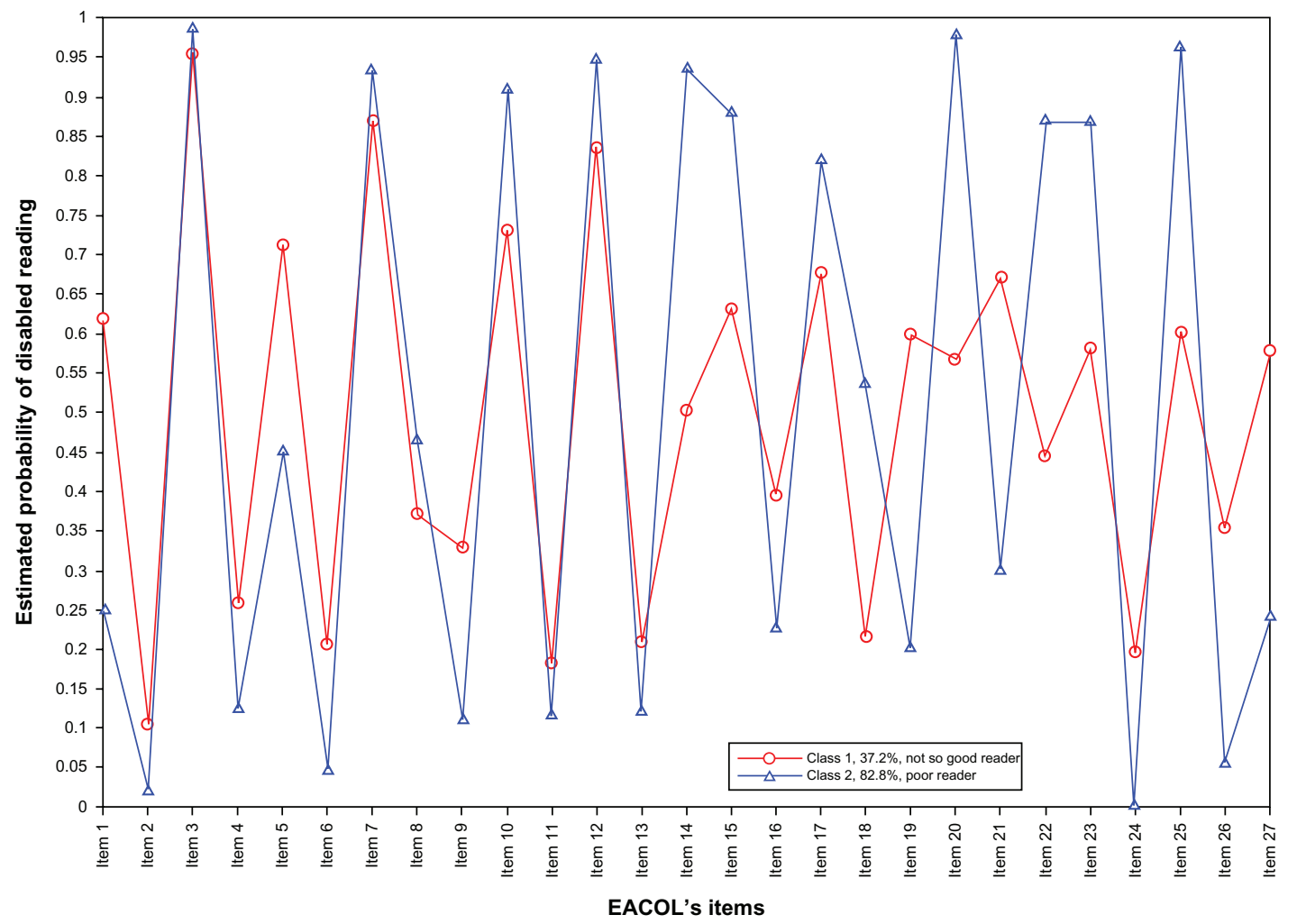

Figure 3 Latent classes analysis for the São Paulo Trial Sample.

Abbreviation: EACOL, Scale of Evaluation of Reading Competence by the Teacher. 
test returned values of $P<0.001$ for the one-, two-, three-, and four-class models, but only the two-class solutions had theoretical and empirical plausibility. Taking Akaike information criterion, BIC, ssaBIC, and entropy results together with the theoretical information about the EACOL and the principle of parsimony, the two-latent-class model was deemed as the most appropriate to describe the data. The model identifies children groups with different patterns of reported reading in both these samples from São Paulo (Table 1).

\section{Description of typological (latent) classification \\ $\mathrm{BH}$-sample}

In this reference sample, a three-class model provided the optimal solution, as observed in Figure 1. Class 1 had model-based prevalence of $26.9 \%$ of the sample, class 2 had $12.1 \%$, and class 3 was the most prevalent at $61.1 \%$. Class 2 is represented by superior marginal probabilities (close to 1), class 3 by inferior marginal probabilities (close to 0 ), and class 1 is represented by the medial line where nonmarginal probabilities occur (the majority of probabilities are centered between 0.25 and 0.75 ). There are three distinct lines which have a small amount of overlap and only two crossed trajectories (items 16 and 17). In the $\mathrm{BH}$, we referred to class 3 as "good readers," class 1 as "not-so-good readers," and class 2 as "poor readers."

\section{São Paulo samples}

The latent structure of the classes in both samples was similar, considering the distribution of estimated probabilities through the 27 items, the number of classes, and the proportion between the percentages of children in each class.

In the graph of the estimated probabilities for SP-screening sample (Figure 2), class 1 comprised $39.7 \%$ of the sample. In the case of the SP-trial (Figure 3), class 1 had a model-based prevalence estimate of $37.2 \%$, and included children with median probabilities (from 0.3 to 0.7 ) in the majority of items reported. We referred to this class as "not-so-good readers."

Class 2 in the SP-trial had a model-based prevalence of $62.8 \%$, and included children who had a marginal value $(P>0.8)$ probability, indicating that eleven out of the 27 EACOL items fit the "poor readers" class. The highest probabilities were observed in the following items: "can summarize the text read orally (item 20);" "can identify characters, places, and ideas in the main text after the first reading (item 25);" and "quickly reads 'known' words and 'little-known' ones (item 12).” In the SP-screening sample, the percentage of the children in class 2 was $60.3 \%$.

The two samples from São Paulo returned similar prevalence for the two latent classes. In addition, it is possible to observe that some items have results with "crossed trends" or even "overlapped trends." This means that these items are not good for discriminating classes and, therefore, could be omitted or excluded in later studies.

With regard to both reading domains (AR and SR) separately, while in BH-sample, RA (from item 1 to item 17) works better, in the samples from São Paulo, SR domain (from item 18 to item 27) better distinguishes the "poor reader" from the "not-so-good" reader class.

Table I Latent class analysis results

\begin{tabular}{|c|c|c|c|c|c|c|c|}
\hline & $\operatorname{BIC}\left(L^{2}\right)$ & $\operatorname{AIC}\left(L^{2}\right)$ & ssaBIC & Entropy & $\begin{array}{l}\text { Parametric } \\
\text { bootstrapped likelihood } \\
\text { HO log likelihood value }\end{array}$ & $P$-value & $\begin{array}{l}\text { Overall bivariate } \\
\text { log-likelihood } \\
\text { Chi-square }\end{array}$ \\
\hline \multicolumn{8}{|c|}{ BH-sample } \\
\hline Model I & 8634.059 & 8531.158 & 8548.413 & - & - & - & 16102.95 \\
\hline Model 2 & 6562.997 & 6353.384 & 6388.533 & 0.987 & -4238.579 & $<0.001$ & 2868.681 \\
\hline Model 3 & 6058.233 & 5768.908 & 5821.95 & 0.975 & -3121.692 & $<0.001$ & 770.341 \\
\hline Model 4 & 6026.771 & 5603.735 & 5674.67 & 0.982 & $-280 I .454$ & $<0.00001$ & 673.126 \\
\hline \multicolumn{8}{|c|}{ SP-screening } \\
\hline Model I & 18317.67 & 18198.19 & 18231.95 & - & - & - & 5558.043 \\
\hline Model 2 & 17173.98 & 16930.62 & 16999.37 & 0.819 & -9072.097 & $<0.001$ & ||98.65| \\
\hline Model 3 & I 7089.5 & 16722.24 & 16825.99 & 0.854 & -8410.308 & $<0.001$ & 832.6 \\
\hline Model 4 & I7078.06 & 16586.9 & 16725.66 & 0.811 & -8278.119 & $<0.00001$ & 686.545 \\
\hline \multicolumn{8}{|l|}{ SP-trial } \\
\hline Model I & 6336.019 & 6242.61 & 6250.44 & - & - & - & I 365.364 \\
\hline Model 2 & 6146.722 & 5956.495 & 5972.455 & 0.827 & -3094.305 & $<0.001$ & 589.026 \\
\hline Model 3 & 6200.666 & 5913.52 & 5937.591 & 0.853 & -2923.247 & $<0.001$ & 456.106 \\
\hline Model 4 & 6253.835 & 5869.821 & 5902.012 & 0.889 & -2874.432 & $<0.001$ & 395.367 \\
\hline
\end{tabular}

Abbreviations: BIC, Bayesian information criterion; AIC, Akaike information criterion; ssaBIC, sample-size adjusted Bayesian information criterion; BH, Belo Horizonte; SP, São Paulo. 


\section{Discriminant and concurrent validity IQ and SDQ}

To test EACOL'S discriminant validity, we used the general IQ and total difficulties children's score in the SDQ as a dependent variable against the same exploratory variable that was used in the above-cited model. We did not observe an association between the latent classes and IQ ( $\beta=6.55$, $P>0.05$ ) and children's total difficulties score measured by the SDQ $(\beta=1.12, P>0.05)$, as observed in the Table 2 , when controlled by age, sex, grade, and school as a cluster unity.

\section{Reading outcomes}

In the regression analyses, the class latent typology had a significant negative association with the three reading measures, controlling for age, grade, sex, and visual acuity and processing auditory status; also the cluster design was considered and consequently, robust standard errors were generated. Results are described in Table 2.

Being a member of the poor-reader class has major negative impact in all reading outcomes, showing that this group has more reading difficulties than the not-so-good readers. For the accuracy of words $(\beta=-11.12, P<0.0001$; in other words, a significant difference of 11 correctly read words per minute between both latent groups of readers) and accuracy of nonwords ( $\beta=-6.50 P<0.001$ ), we used Tobit regression due to the floor effects in both continuous outcomes (children who read zero words/nonwords correctly) and, therefore, we specified one left-censoring limit of 1 correctly read word per minute. For the accuracy of text reading $(\beta=-11.27$, $P<0.01$ ), a linear-regression model was used, showing that there is an effect of being class 1 or 2 on the outcome. More precisely, comparing not so good readers and poor readers, we expected that the worst indicators of reading would be achieved from poor readers (class 2).

\section{Discussion}

The present study explored the predictive ability of indirect measures of teachers' reports of children's reading ability.
The latent groups of readers predicted direct measures of reading abilities, particularly in the area of decoding of isolated words (represented here as accuracy of word and nonword reading) and words in context (represented as the accuracy of reading text). Considering the SP-trial, the poor-reader latent group correctly read 6.50 nonwords less per minute than did the not-so-good readers. Also, in the other reading measures, the differences between both groups are statistically significant: the poor-reader latent group's performance was worse than that of the not-so-good-reader group regarding accuracy of reading both isolated words and words in context (difference of 11.12 and 11.27 correctly read words per minute, respectively) (Table 1). These results are evidence of the concurrent validity of the EACOL.

We also evaluated the extent to which the instructions given to the teachers could accurately affect the identification of the latent groups of readers.

\section{Major findings and clinical implications}

The BH sample returned a three-class model while SP samples returned a two-class model due to the instructions that were given to the teachers. As a consequence, the number of returned classes must be different, giving evidence for the concurrent validity of the EACOL. Considering that in the BH-sample the EACOL covered the full spectrum of the reading abilities (ie, no discriminative instruction was given to the teachers), the BH-sample prevalence results may suggest either that the teacher has a tendency to overestimate the children's reading ability, or that perhaps teachers tend to or even prefer to answer about children who have nonspecific academic difficulties of some sort. Since the EACOL inquires about specific characteristics of children's reading, which normally are observable one-by-one, it is necessary to have a proximal contact with the child, especially to evaluate items related to silent reading, which showed better discrimination in SP-sample (ie, samples of children with reading difficulty). Therefore, when no specification of the type of reading ability of the participants is requested, teachers may tend to complete

Table 2 Values for regression coefficients with its respective robust standard error, $P$-value and $95 \%$ confidence interval for variables of concurrent and discriminant validity

\begin{tabular}{|c|c|c|c|c|c|c|}
\hline & $\begin{array}{l}\text { Outcomes on two latent } \\
\text { groups from LCA }\end{array}$ & Coefficient ( $\beta$ ) & $\begin{array}{l}\text { Robust standard } \\
\text { error }\end{array}$ & $t$ & $P$-value & $\begin{array}{l}95 \% \text { confidence } \\
\text { interval }\end{array}$ \\
\hline Concurrent & Accuracy of nonword & -6.50 & 1.546 & -4.21 & $<0.001$ & -9.55 to -3.45 \\
\hline \multirow[t]{2}{*}{ validity } & Accuracy of word & -11.12 & 2.672 & -4.16 & $<0.001$ & -16.39 to -5.85 \\
\hline & Accuracy of text & -11.27 & 3.732 & -3.02 & 0.014 & $-19.7 \mid$ to -2.83 \\
\hline Discriminant & IQ total & 1.12 & 0.845 & 1.33 & 0.217 & -0.79 to 3.03 \\
\hline validity & Total difficulties score (SDQ) & -1.60 & 1.604 & -1.00 & 0.344 & -5.23 to 2.03 \\
\hline
\end{tabular}

Abbreviations: LCA, latent class analysis; SDQ, Strengths and Difficulties Questionnaire. 
the EACOL considering predominantly the children with good and not so good reading abilities (the major prevalence groups in the BH-sample).

We expected to observe proportions among the three classes to be similar to the normal curve, with the majority of the children categorized around the mean (corresponding to the average reader, here the "not-so-good reader") and the minority (both good and poor readers) placed with regard to the marginal probabilities, closer to 0 and closer to 1 , respectively.

The BH sample returned a three-class model, while SP samples returned a two-class model, due to the instructions given to the teachers. As a consequence, the number of returned classes must be different, giving evidence for the concurrent validity of EACOL.

As can be seen in Table 1, the entropy values (ie, how well the classes are distinguished from each other) in both samples from São Paulo are lower than in the sample from $\mathrm{BH}$. This could refer to the difficulty of teachers in evaluating children due to the instructions, especially those who had reading difficulties. Taking into consideration the BH-sample, a three-class solution was achieved and only two items had "crossed values." Therefore, when no instruction is given to the teachers, distinctions amongst the three reading categories is more precise than when a restriction is given.

Taking the two domains of the scale RA and SR into account, some details could be addressed about the 27 items. In the cases of SP-trial and SP-screening, it is possible to observe in the graphs of estimated probabilities, a major overlapping in the RA domain (ie, represented by two lines closer or with the same trajectory), whereas in the SR domain the two lines do not overlap.

In the BH-sample, in which the good readers and not-so-good readers (Figure 1: classes 3 and 1, respectively) have very close probabilities $(P<0.1)$, taking into account five of the ten items (items 19, 20, 21, 22, 23), RA was found to work better than SR. In RA, the item 15 ("reads with rhythm, not too slowly nor too quickly") did not have the probability to discriminate the classes of "good reader" and "not-so-good reader," because there was an overlap between two classes in the same probability. With the exception of this item, RA seems to better differentiate the classes when no direction is given to teachers, probably because in the school context it might be easier to observe difficulties in reading aloud than in silent reading (as evaluation of this latter type of reading is often obtained "head-to-head"), through specific investigation and inquiry about the students' comprehension capacity (such as his/her ability to use knowledge of world to make inferences and to monitor the understanding of what is being read). ${ }^{28} \mathrm{On}$ the other hand, when teachers were required to think about the children with reading difficulties, SR became a better measure by which to distinguish not-sogood readers from poor readers, since, in this condition, the overlapping of trajectories among the items was less frequent. With respect to discriminant validity, the latent groups in SP-trial did not predict the total score in the Wechsler Intelligence Scale, as found also by Hatcher and Hulme, ${ }^{29}$ or SDQ as expected, showing that both of these domains were not associated with reading skills. More specifically, children's behavioral characteristics evaluated via SDQ were not taken into account in teachers' evaluations of children's reading. In other words, teachers were capable of distinguishing the presence of behavioral problems from reading difficulties, indicating that they evaluated both theoretical constructs domains independently. This is in disagreement with the finding that the teachers' perceptions of their students' behavior constituted a significant component of the judgments made about their students' scholastic achievements. ${ }^{30}$

Therefore, this study found evidence that the EACOL is a reliable instrument by which to assess reading via teachers' judgment. Since it is simple and easy to administer, it is an important tool to help a wide range of professionals (eg, health professionals who work with children, teachers and educators, and researchers).

\section{Acknowledgment}

This study was funded by the National Council for Scientific and Technological Development (CNPq - grant No 482321/2010-5) and the Instituto ABCD, which is a nongovernmental organization that supports research about dyslexia in Brazil.

\section{Disclosure}

JJM, HCM, GBP, and CRM conducted a randomized clinical trial about the effectiveness of music education among children with reading difficulties. EACOL was used as a screening tool in selected children with reading difficulties. CRBA recently received a grant (São Paulo Research Foundation grant number 2011/11369-0) to develop a tool to evaluate reading comprehension among schoolchildren. HCM received a PhD scholarship from CNPq and CAPES Foundation, an agency under the Ministry of Education of Brazil, in order to conduct part of his doctoral research as a visiting graduate student at London School of Hygiene and Tropical Medicine. 


\section{References}

1. Elliott SN, Gresham FM, Freeman T, McCloskey G. Teacher and observer ratings of children's social skills: validation of the Social Skills Rating Scales. J Psychoeduc Assess. 1988;6(2): 152-161.

2. Gerber MM, Semmel MI. Teacher as imperfect test: reconceptualizing the referral process. Educ Psychol. 1984;19(3):137-148.

3. Hoge RD, Coladarci T. Teacher-based judgments of academic achievement: a review of literature. Rev Educ Res. Fal 1989;59(3):297-313.

4. Salinger T. Assessing the literacy of young children: the case for multiple forms of evidence. In: Neuman SB, Dickinson DK, editors. Handbook of Early Literacy Research. New York: Guilford Press; 2002;1: 390-418.

5. Cabell SQ, Justice LM, Zucker TA, Kilday CR. Validity of teacher report for assessing the emergent literacy skills of at-risk preschoolers. Lang Speech Hear Serv Sch. 2009;40(2):161-173.

6. Schatschneider C, Petscher Y, Williams KM. How to evaluate a screening process: the vocabulary of screening and what educators need to know. In: Justice LM, Vukelich C, editors. Achieving Excellence in Preschool Literacy Instruction. New York: Guilford Press; 2008:304-316.

7. Snowling MJ, Duff F, Petrou A, Schiffeldrin J, Bailey AM. Identification of children at risk of dyslexia: the validity of teacher judgements using 'Phonic Phases'. J Res Read. May 2011;34(2):157-170.

8. Snowling MJ, Hulme C. Annual research review: the nature and classification of reading disorders - a commentary on proposals for DSM-5. J Child Psychol Psychiatry. 2012;53(5):593-607.

9. Pinheiro AMV. Heterogeneidade entre leitores julgados competentes pelas professoras [Heterogeneity among readers judged as competent by teachers]. Psicol Refl Crit. 2001;14(3):537-551. Brazilian Portuguese.

10. Pinheiro AMV, Costa AEB. Os passos da construção da Escala de Avaliação de Competência de Leitura de alunos pelo professor - EACOL [The development of the Scale of Evaluation of Reading Competence by the Teacher - EACOL]. Paper presented at: VII Internacional de Investigação em Leitura, Literatura Infantil e Ilustração Meeting; 2012 Sep 17-19; Braga, Lisbon. Portuguese.

11. Pinheiro AMV, Costa AEB. Escala de avaliação de competência em leitura pelo professor [Scale of Evaluation of Reading Competency by the Teacher]. Paper presented at: VII Encontro Mineiro de Avaliação Psicológica 2005; Belo Horizonte, Brazil. Brazilian Portuguese.

12. De Salles JF, Parente MAMP. Relação entre desempenho infantil em linguagem escrita e percepção do professor [Children's performance in written language and perception of teacher]. Cad Pesqui. 2007;37(132): 687-709. Brazilian Portuguese.

13. Pinheiro AMV. Validação e Estabelecimento de Normas de Uma Prova Computadorizada de Reconhecimento de Palavras Para Crianças. Belo Horizonte: Federal University of Minas Gerais; 2012. SHA - APQ01914-09.

14. Urbina S. Essentials of Psychological Testing. Hoboken: John Wiley \& Sons; 2004.
15. Pasquali L, Wechsler S, Bensusan E. Matrizes Progressivas do Raven Infantil: um estudo de validação para o Brasil [Raven's Colored Progressive Matrices for Children: a validation study for Brazil]. Aval Psicol. 2002;1(2):95-110. Brazilian Portuguese.

16. Raven J. Raven's Progressive Matrices and Vocabulary Scales. London: HK Lewis; 1986.

17. Wechsler D. WISC-III: Wechsler Intelligence Scale for Children. San Antonio: The Psychological Corporation; 1991.

18. Goodman R. The Strengths and Difficulties Questionnaire: a research note. J Child Psychol Psychiatry. 1997;38(5):581-586.

19. Pinheiro AMV. Contagem de Frequência de Ocorrência de Palavras Expostas a Crianças na Faixa Pré-escolar e Séries Iniciais do $1^{\circ}$ Grau [Count Frequency of Word Occurrence Amongst Preschoolers and Elementary School Children]. Sao Paulo (SP): Associação Brasileira de Dislexia; 1996. Brazilian Portuguese.

20. Pinheiro AMV. [Anexo 2.] In: Sim-Sim I, Vianna FL, editors. Para a Avaliação do Desempenho de Leitura [Reading Achievement Performance Evaluation]. Lisbon: Gabinete de Estatística e Planeamento da Educação; 2007:121-131. Brazilian Portuguese.

21. Capovilla AGS, Capovilla FC. Prova de consciência fonológica: desenvolvimento de dez habilidades da pré-escola à segunda série [Phonological Awareness Test: development of ten abilities from preschool to third grade]. Temas Desenvolv. 1998;7(37):14-20. Brazilian Portuguese.

22. Lazarsfeld PF, Henry NW. Latent Structure Analysis. Boston: Houghton Mifflin; 1968.

23. Engelmann L, Ferreira MIDC. Avaliação do processamento auditivo em crianças com dificuldades de aprendizagem [Auditory processing evaluation in children with learning difficulties]. Rev Soc Bras Fonoaudiol. 2009;14(1):69-74. Brazilian Portuguese.

24. Clogg CC. Latent Class Models. New York: Plenum; 1995.

25. Everitt BS, Hand DJ. Finite mixture distributions. In: Cox DR, Isham N, Keiding T, et al, editors. Monographs on Applied Probability and Statistics. London: Chapman and Hall; 1981.

26. Magidson J, Vermunt J. Latent class models for clustering: A comparison with K-means. Canadian Journal of Marketing Research. 2002;20(1):37-44.

27. Muthén L, Muthén B. Statistical Analysis with Latent Variables: User's Guide. 4th ed. Los Angeles: Muthén \& Muthén; 1998-2011.

28. Ricketts J. Research review: reading comprehension in developmental disorders of language and communication. Jf Child Psychol Psychiatry. 2011;52(11):1111-1123.

29. Hatcher PJ, Hulme C. Phonemes, rhymes, and intelligence as predictors of children's responsiveness to remedial reading instruction: evidence from a longitudinal intervention study. J Exp Child Psychol. 1999;72(2):130-153.

30. Bennett RE, Gottesman RL, Rock DA, Cerullo F. Influence of behavior perceptions and gender on teachers' judgments of students' academic skill. J Educ Psychol. 1993;85(2):347-356. 


\section{Supplementary material}

Figure S1 EACOL form B

Student's name:

School year:

Age: ___ years months

Teacher's name:

School's name:

\begin{tabular}{|c|c|c|c|c|}
\hline $\mathbf{N}^{\circ}$ & Subtypes of readers & Criterion & Yes & No \\
\hline \multicolumn{5}{|c|}{ Evaluation of reading aloud } \\
\hline 01 & Poor reader & Reads but cannot tell what was read, even when stimulated with questions. & & \\
\hline 02 & Not-so-good reader & Sometimes makes mistakes when reading "new" words. & & \\
\hline 03 & Good reader & $\begin{array}{l}\text { Reads with intonation compatible with the punctuation marks, expressing } \\
\text { emotions and feelings according to the text read. For example, } \\
\text { gives an intonation of questioning in the whole sentence, when there } \\
\text { is a question mark in the text. Gives intonation of joy or surprise, } \\
\text { in the whole sentence, when there is an exclamation mark. }\end{array}$ & & \\
\hline 04 & Poor reader & $\begin{array}{l}\text { Does not take into account the intonation compatible } \\
\text { with the punctuation marks, reading in a monotone manner. }\end{array}$ & & \\
\hline 05 & Poor reader & Says "I do not know" when encounters a new word. & & \\
\hline 06 & Not-so-good reader & Sometimes reads and cannot retell what was read. & & \\
\hline 07 & Good reader & Quickly reads "new" and invented words. & & \\
\hline 08 & Poor reader & $\begin{array}{l}\text { Reads very slowly, without rhythm, spelling out each syllable; does } \\
\text { not observe the punctuation marks. }\end{array}$ & & \\
\hline 09 & Poor reader & Reads by spelling out both "new" and "known" words. & & \\
\hline 10 & Not-so-good reader & $\begin{array}{l}\text { Sets the tone of interrogation and/or exclamation only in the word } \\
\text { that precedes the punctuation mark. }\end{array}$ & & \\
\hline 11 & Not-so-good reader & $\begin{array}{l}\text { Slows the rhythm of reading when "new" words are encountered, } \\
\text { needing to spell them out. }\end{array}$ & & \\
\hline 12 & Good reader & Quickly reads the "known" words and the "little-known" ones. & & \\
\hline 13 & Poor reader & Often makes mistakes when reading "new" words. & & \\
\hline 14 & Good reader & Seems to have understood what was read when asked about the text read. & & \\
\hline 15 & Good reader & Reads with rhythm, not too slowly nor too fast. & & \\
\hline 16 & Not-so-good reader & Reads too slowly or too quickly. & & \\
\hline 17 & Good reader & Reads words correctly. & & \\
\hline \multicolumn{5}{|c|}{ Evaluation of silent reading } \\
\hline 18 & Not-so-good reader & $\begin{array}{l}\text { Does identify characters and places, but has some difficulty identifying } \\
\text { main ideas without a second reading. }\end{array}$ & & \\
\hline 19 & Poor reader & Does not identify the subject from the title, nor vice versa. & & \\
\hline 20 & Good reader & Can summarize the text read orally. & & \\
\hline 21 & Poor reader & Does not identify characters, places, or main ideas expressed in the text. & & \\
\hline 22 & Good reader & $\begin{array}{l}\text { Is able to choose a title for passages presented with no title or even give an } \\
\text { alternate title for titled passages. }\end{array}$ & & \\
\hline 23 & Good reader & Is able to identify the subject from the title and vice versa. & & \\
\hline 24 & Not-so-good reader & Presents some difficulty in orally summarizing what was read. & & \\
\hline 25 & Good reader & Can identify characters, places, and ideas in the main text after the first reading. & & \\
\hline 26 & Not-so-good reader & Not always able to identify the subject from the title and vice versa. & & \\
\hline 27 & Poor reader & Not able to summarize what was read, either orally or in writing. & & \\
\hline
\end{tabular}




\section{Publish your work in this journal}

Neuropsychiatric Disease and Treatment is an international, peerreviewed journal of clinical therapeutics and pharmacology focusing on concise rapid reporting of clinical or pre-clinical studies on a range of neuropsychiatric and neurological disorders. This journal is indexed on PubMed Central, the 'PsycINFO' database and CAS.

The manuscript management system is completely online and includes a very quick and fair peer-review system, which is all easy to use. Visit http://www.dovepress.com/testimonials.php to read real quotes from published authors.

\footnotetext{
Submit your manuscript here: http://www.dovepress.com/neuropsychiatric-disease-and-treatment-journal
} 